\title{
Seroprevalence of Salmonella Gallinarum Infection in Chicken Population of parts of Tigray and Addis Ababa by Plate Agglutination and Micro- agglutination Tests
}

\author{
Ashwani Kumar*, Etsay Kebede, Yohaness Tekle, Tsegabirhan KifleYohannes, \\ Kassaw Amsalu and Tsegay Tkue \\ College of Veterinary Medicine, Mekelle University, P.O. Box 231, Mekelle, Ethiopia \\ (*ashwanivet126@yahoo.com).
}

\begin{abstract}
Ethiopia owns a large poultry population whose growth is highly constrained by diseases. Fowl typhoid is a serious concern in growing and adult poultry and results from infection by Salmonella Gallinarum (Salmonella enterica subsp. enterica serovar Gallinarum biovar Gallinarum). Knowledge of the prevalence of the disease with confirmatory diagnosis is of paramount importance to embark on a control or prevention program. Seroprevalence of this infection in chicken population of Ethiopia has been reported from some parts of this country but in most of the reports it is based exclusively on a rapid slide agglutination test without further confirmation by another specific test. This study screened 279 sera samples of poultry for S. Gallinarum infection by employing plate agglutination test using colored antigen of S. Gallinarum that revealed $125(44.80 \%)$ of 279 sera samples positive. However, when plate positive samples were further tested for confirmation by microagglutination test by employing plain antigen of S. Gallinarum, only $55(19.71 \%)$ were serologically positive lowering the prevalence rate from $44.8 \%$ to $19,71 \%$. The study reveals the serological prevalence of Salmonella gallinarum infection in poultry population of the study areas and recommends that the initial screening of this infection by a test like plate agglutination must always be followed by another specific test to get an accurate estimate of this infection.
\end{abstract}

Keywords: Micro-agglutination test, Plate agglutination test, Poultry population, Salmonella gallinarum, Seroprevalence, Addis Ababa, Tigray, Ethiopia.

\section{INTRODUCTION}

The mortality due to diseases in day old to adult chicken in Ethiopia is estimated to be 20 to 50\% (Kassaye et al., 2010). Fowl typhoid and Pullorum disease are expected to incur heavy losses to the poultry industry in Ethiopia as it is the case in other African countries (Bell et al., 1990; Bouzoubaa et al., 1992; Chrysostome et al., 1995; Sato et al., 1997). It is a serious concern in growing and adult poultry and results from infection by Salmonella Gallinarum (Salmonella enterica subsp. enterica serovar Gallinarum biovar Gallinarum). The clinical signs include decreased appetite, depression, dehydration, weight loss, ruffled feathers, and pale shrunken combs. Confirmatory diagnosis depends on the isolation of the organism while serological tests are satisfactory for establishing the presence and estimating the prevalence of infection within a flock (OIE, 2008). The most readily applied tests include rapid whole blood agglutination, rapid serum agglutination (RST), tube agglutination, micro-agglutination 
and ELISA (USDA, 1996; Barrow, 1992). An initial screening of sera by RST followed by confirmation of positive by the tube agglutination test is the optimal approach (Shivaprasad, 1997). Serological and bacteriological reports confirmed the presence of $S$. Gallinarum/Pullorum in chickens in Ethiopia (Kassaye et al., 2010; Netsanet, et al., 2012). Serological reports are, however, mainly based on rapid screening by plate agglutination test (Melese, 1991; Assefa, 1992; Netsanet et al., 2012) without confirmation of positive reactions by more specific agglutination test. This study screened the sera samples of poultry in Mekelle and surrounding areas (Adigret, Hagersalem, Wukro) and Debrezeit (Addis Abeba) by plate agglutination test using colored antigen of Salmonella gallinarum. The positive reactions were further titrated for confirmation by microagglutinatiom test using plain agglutination antigen of this species of Salmonella.

\section{MATERIALS AND METHODS}

\subsection{Study Area}

The study area included Debrezeit (Addis Abeba), Mekelle and surrounding areas of Adigret, Hagersalem, Wukro.

\subsection{Study Animals}

The target populations were of adult chicken maintained at commercial and local chicken farms as well as chicken at poultry abattoirs.

\subsection{Study design and sample size}

Samples were collected by random sampling from purposely selected poultry farms in the study areas. Sample size was determined by the sample collection up-to saturation and according to owner's willingness. A total of 279 blood samples were collected aseptically in sterile disposable tubes that were kept for 3-4 hours at room temperature followed by storage in refrigerator for maximum yield of serum. The sera were stored in sterile labeled cryovials in a deep freeze at $-20^{\circ} \mathrm{C}$ until tested.

\subsection{Serological testing}

All the collected sera were first tested by slide agglutination test as a screening test. The samples giving positive results were then confirmed by microagglutination test using plain antigen of S.Gallinarum obtained from National Veterinary Institute, Debrezeit, Addis Abeba. 


\subsection{Rapid plate agglutination test}

The test was performed according to the procedure described in OIE (2012). One drop (about $0.02 \mathrm{ml}$ ) of crystal-violet-stained antigen was placed in the centre of a glass slide and an equal size of serum next to a drop of antigen. The drops of antigen and serum were mixed using a tooth prick. The results were observed within two minutes. A reaction indicating easily visible clumping of the antigen within 2 minutes was considered as positive while a negative reaction was indicated by absence of clumping of the antigen within 2 minutes. Known positive and negative control sera were included on each testing occasion, using them in the same way as the serum.

\subsection{Micro-agglutination test}

This test was performed in microtiteration plates. Sera were first diluted by adding $10 \mu 1$ of serum to $90 \mu \mathrm{l}$ of normal saline, and then adding $100 \mu \mathrm{l}$ of Salmonella Gallinarum plain antigen to give a final dilution of $1 / 20$. This was further diluted in doubling dilution to get a dilution of 1/40. A positive control using known positive serum in 1/20 and 1/40 dilutions and antigen was included in each plate. The plates were sealed and incubated at $37^{\circ} \mathrm{C}$ for $18-$ 24 hrs. A positive reaction consisted of a fine diffuse precipitation, whereas a negative reaction showed a button-like precipitate. Titers of 1/40 were considered to be positive (OIE, 2012)

\subsection{Data Analysis}

Seroprevalence was calculated by dividing the total number of S. Gallinarum seropositive chicken by the total number of chicken examined and multiplied by hundred (Thrusfield, 1995 as cited in Netsanet et al., 2012 )

\section{RESULTS}

Sero-prevalence of S.Gallinarum in chicken population of study area is given in table 1 where out of the total 279 serum samples, 125 (44.8\%) were positive to slide agglutination test. The slide agglutination test positive sera when tested for confirmation by micro-agglutination test, only 55 (19.71\%) were found positive. The overall sero-prevalence of S. Galinarum was estimated to be $19.71 \%(55 / 279)$ (Table 1$)$. 
Table 1. Seroprevalence of Salmonella gallinarum by plate agglutination test and microagglutination test.

\begin{tabular}{|ccccc|}
\hline $\begin{array}{c}\text { Total number of } \\
\text { sera samples tested }\end{array}$ & \multicolumn{2}{c}{ Number of sera samples positive by } & \multicolumn{2}{c|}{ Sero-prevalence (\%) by } \\
\cline { 2 - 5 } & $\begin{array}{c}\text { Slide agglutination } \\
\text { test }\end{array}$ & $\begin{array}{c}\text { Micro- } \\
\text { agglutination test }\end{array}$ & $\begin{array}{c}\text { Slide } \\
\text { agglutination } \\
\text { test }\end{array}$ & $\begin{array}{c}\text { Micro- } \\
\text { agglutination } \\
\text { test }\end{array}$ \\
\hline 279 & 125 & 55 & $44.8 \%$ & $19.71 \%)$ \\
\hline
\end{tabular}

\section{DISCUSSION}

Seroprevalence varying from $10.44 \%$ to $64.2 \%$ is on record from different parts of Ethiopia like Shola, Addis Abeba, Denbi, eastern and central Ethiopia and Mekelle (Melese,1991; Assefa, 1992; Yang et al., 1996; Ashenafi et al., 2003; Netsanet et al., 2012). In a recent study by Netsanet et al. 2012, the prevalence of S. pullorum in and around Mekelle was recorded as $32.8 \%$ and the test employed was the slide agglutination test using colored antigen of Salmonella Gallinarum/pullorum. The overall sero-prevalence of S.Gallinarum reported in this study is $19.71 \%$ which is much lower than the recently reported prevalence of $32.8 \%$ (Netsanet et al., 2012). This variation may be due to screening of the sera samples by slide agglutination test followed by confirmation of slide positive sera samples by microagglutination test. The test used in the most of the studies on seroprevalence of poultry salmonellosis in Ethiopia (Melese, 1991; Assefa, 1992; Yang et al., 1996; Ashenafi et al., 2003; Netsanet et al., 2012) are based on a rapid whole blood/serum plate agglutination test that is a screening test but unreliable as many uninfected birds may give positive reactions(OIE, 2012). An initial screening of sera by rapid slide test followed by confirmation of positive by the tube agglutination test is the optimal recommended approach (Shivaprasad, 1997) for serological diagnosis of poultry salmonellosis which has not been followed in most of the earlier studies.

Fowl typhoid is an economically important disease, without their effective control through organized national regulatory programs; the profitable production of poultry would be impossible (Williams and Whitemore, 2007). However, for the effective control, an accurate assessment of the disease in poultry flocks has its own significance which should not be restricted to screening test but always be followed by confirmatory serological test or bacteriological isolation. 


\section{ACKNOWLEDGMENTS}

The authors acknowledge Mekelle University NORAD III Project Coordinator for extending the financial support to undertake this research work. The authors also extend their thanks to College of Veterinary Medicine, Mekelle University, Ethiopia for providing necessary facilities for research.

\section{REFERENCE}

Ashenafi, H., Eshetu, Y \& Woldmeskel, M. 2003. Identification of major infections of local chickens of Central Ethiopia. Bulletin of Animal Health and Production in Africa, 51:95-101.

Assefa, W. 1992. Sero-epidemiological survey of S.pullorum/gallinarum infection in small scale poultry farms and backyard farms in and around Addis Ababa.

Barrow, P. A. 1992. ELISAs and the serological analysis of Salmonella in poultry: a review. Epidemiology and Infection, 109: 361-369.

Bell, J.G., Kane, M \& Lejan, C. 1990. An investigation of the disease status of village poultry in Mauritania. Preventive Veterinary Medicine, 8: 291-294.

Bouzoubaa, K., Lemainguer, K \& Bell, J. G. 1992. Village chickens as a reservoir of Salmonella Pullorum and Salmonella Gallinarum in Morocco. Preventive Veterinary Medicine, 12: 95-100.

Chrysostome, C.A.A.M., Bell, J.G., Demey F \& Verhulst, A. 1995. Sero prevalences to three diseases in village chickens in Benin. Preventive Veterinary Medicine, 22: 257-261.

Kassaye Aragaw, Lencho Terefe and Mesele Abera. 2010. Prevalence of Salmonella Infection in Intensive Poultry Farms in Hawassa and Isolation of Salmonella species from sick and dead chickens. Ethiopian Veterinarian Journal, 14(2), 115-124.

Melese, G. 1991. Sero-epidemiological study of S.pullorum/gallinarum infection in Shola and Denbi state poultry farms using R.B.A.T. (cited by Netsanet Berhe et al, 2012).

Netsanet Berhea, Berihun Aferaa, Nigus Abebea, Abreha Tesfaya \& Shewit Kalayou. 2012. Seroprevalence of Salmonella pullorum infection in local andexotic commercial chiken from Mekelle areas, northern Ethiopia. REDVET - Revista electrónica de Veterinaria, 13(9):1-11(http://www.veterinaria.org/revistas/redvet/n090912.html).

OIE. 2008. Fowl typhoid and pullorum disease. In: Terrestrial Manual. Office International des Epizooties (OIE), Paris, France, pp.538-548. 
OIE. 2012. Fowl typhoid and pullorum disease. In: Manual of diagnostic tests and vaccines for terrestrial animals. Chapter 2.3.1, ISBN 978-92-9044-875-5 (Retrieved at http://www.oie.int/international-standard-setting/terrestrial-manual).

Sato, Y., Sato, G., Tuchili, L., Pandey, G.S., Nakajima, A., Chimana, H \& Sinsungwe, H. 1997. Status of Salmonella Gallinarum-Pullorum infections in poultry in Zambia. Avian Diseases, 41:490-495.

Shivaprasad , H. L. 1997. Pullorum disease and fowl typhoid. Iowa State University Press, Ames, Iowa, USA, pp. 82-96.

Thrusfield, M. 1995 . Veterinary Epidemiology, $2^{\text {nd }}$ edition, Blackwell Science Ltd., UK.

USDA. 1996. Auxiliary Provisions on National Poultry Improvement Plan. Code of Federal Regulations, 9(147):717-727.

Williams, J. E \& Whitemore, A.D. 2007.Serological diagnosis of pullorum disease with the microagglutination system. Applied Microbiology, 21:394-399.

Yang, Y. C., Sun, Y., Wang, M. M., Li, Y. K., Zhang, X. X \& Sun, B. A. 1996. Discussion of onsite detection of pullorum disease in breeding chickens and control measures. Chinese Journal of Veterinary Medicine, 22:20-22. 